\title{
Papéis e funções dos/as adultos/as e das crianças na família. As conceções das crianças de um jardim de infância
}

\section{Family roles of adults and children. Kindergarten children's conceptions}

\author{
Joana Pereira*, Catarina Tomás** \\ *Escola Superior de Educação de Lisboa, **UMINHO
}

\begin{abstract}
Resumen
O estudo de caso que se apresenta foi realizado num jardim de infância de Lisboa, com um grupo de 19 crianças entre os 5 e os 6 anos, e teve com objetivo compreender as suas representações e perspetivas face à realidade social e familiar da atualidade, geralmente estudadas através do olhar adulto. A partir de uma metodologia qualitativa, as conclusões remetem para a assunção, pelas crianças, de que as suas funções na família se centram no respeito pela ordem e superioridade adulta, numa lógica de conformismo associada à (ir)responsabilidade que relacionam à condição da infância.

Palabras clave: infância, família, jardim de infância
\end{abstract}

\begin{abstract}
The present case study was carried out in a kindergarten in Lisbon with a group of 19 children between aged of 5-6. The aim was to understand their social representations and perspectives regarding the social and family reality of the present time, usually studied through the adult point of view. From a qualitative methodology, the conclusions refer to the assumption by the children that their functions in the family are centred on respect for adult order and superiority, in a logic of conformism related with the (ir)responsibility they relate to the condition of childhood.

Keywords: childhood, family, kindergarten
\end{abstract}

"O que é ser pai e mãe?" Análise dos discursos das crianças da sala 1

De acordo com Graça (2015), torna-se relevante considerar que o lugar da criança na família não existe enquanto figura homogénea. De igual modo, observa-se uma grande heterogeneidade relativamente à sua condição de filhos/as e à forma como as crianças experienciam, sentem e vivem os seus contextos familiares (p. 55). Assim, importou na investigação realizada ter em conta as suas vozes, entendendo as suas conceções face ao papel assumido pelos/as adultos/as no seio familiar. No que diz respeito à função dos/as adultos/as (pai e mãe), identificaram-se assim três dimensões significativas, associadas aos papéis que estes assumem, na ótica das crianças, na família: (i) proteção; (ii) instrumental; e (iii) papéis sociais genderizados. Já no que diz respeito à sua condição de filho/a, enquanto membro pertencente a uma família, os discursos das crianças apontavam para a existência de dois grandes ofícios associados à infância: ser filho/a e ser criança.

\section{Nota metodológica e ética}

Tratou-se de uma investigação qualitativa que decorreu no ano letivo de 2016/2017 numa sala de jardim de infância da cidade de lisboa. Optou-se por recolher os dados a partir da observação e da realização de grupos de discussão focalizada com as crianças. Após os dados recolhidos procedeu-se à análise de conteúdo (Bardin, 1979). De referir que foi promovido um roteiro ético que garantiu e assegurou a confidencialidade dos dados recolhidos, bem como o consentimento informado de todos/as os/as participantes envolvidos/a (adultos/as e crianças). Considerando que a compreensão das representações e perspetivas das crianças face à realidade social e familiar são quase sempre estudadas através do olhar adulto, a investigação realizada pretendeu ser um contributo para a desocultação daquilo que as crianças pensam sobre si e sobre as suas famílias, a partir de uma complexa teia de relações e pertenças, uma vez que estas assumem uma duplicidade de ofícios - criança, aluno/a e filho/a.

Como Ferreira (2006) afirma, as crianças "[são] olhadas mas não observadas, ouvidas mas não escutadas, são silenciadas, uma vez que os adultos, continuando do "lado de cá", ou podendo até "estar lá" [não estão verdadeiramente com as crianças]" (p. 149). Assim, escutar o que elas têm para nos dizer, pode, muitas vezes, desocultar sentimentos ou perspetivas que estas têm sobre o mundo adulto, pertinentes a uma verdadeira análise da infância enquanto categoria social e promovendo uma prática pedagógica verdadeiramente contextualizada.

\section{Dimensão de proteção}

Para as crianças, é sobretudo a dimensão de proteção aquela que os pais e mães devem assumir relativamente a si mesmas. Da análise dos dados, identificaram-se duas subcategorias presentes nos seus discursos sobre a função dos/as adultos/as: o cuidado e a regulação do 
comportamento das mesmas. Quanto ao cuidado, interligado à definição de função de papel (Cunha, 2007), este surgiu quase sempre relacionado com a responsabilidade que a condição adulta implica, na garantia dos cuidados quotidianos prestados aos filhos: "Diogo (6 anos): ser pai é ser responsável e cuidar dos filhos. Martim (6 anos): sim, têm de ser muito responsáveis" (nota de campo 6 jan, 2017). Possivelmente por associarem a responsabilidade a algo de cariz adulto - ser responsável por um outro ser humano -, algumas crianças afirmavam que só quando se tornassem adultas é que seriam responsáveis, restringindo essa competência a um mundo que ainda parece não ser o seu. Não podendo generalizar essa constatação, verificou-se como um pouco mais notória a aceção do cuidar, na sua essência de prestação de cuidados e dedicação ao outro, entendida "como o próprio ser da existência na sua capacidade de projetar-se a si mesmo e de poder-ser" (Nörnberg, 2007, p. 213). Por meio de uma lógica de reprodução social, através da brincadeira, surge uma ilustração clara da visão de uma criança sobre o mundo adulto, um mundo cheio de exigências e responsabilidades. Não obstante, para além dessas condicionantes, as crianças identificavam ainda uma outra função: a regulação do comportamento da criança, onde era aparentemente visível a associação deste domínio ao processo de emancipação, de crianças a adultos. Como defendem Christensen e James (2005), as crianças continuam a ter uma voz apagada no contexto familiar: "Filipe: (...) eles é que mandam! Quando eu for adulto vou mandar também" (13 jan, 2017).

\section{Dimensão instrumental}

Para além da dimensão da proteção, destacou-se ainda, nos discursos das crianças, a dimensão instrumental associada à função dos/as adultos/as em relação aos/às filhos/as, centrada em duas óticas: a económica/material e a companhia/auxílio. Relativamente à ótica económica/material, constatou-se a relevância dada à capacidade, responsabilidade e autonomia económica/financeira dos adultos. As crianças referiram a necessidade do sustento da família e a independência que esta autonomia e condição adulta lhes conferia. Numa outra perspetiva, esta dimensão parecia emergir associada a uma lógica de recompensa, atribuída na relação pais/mães-filhos/as, onde o 'bom comportamento' da criança surgia como meio de alcance de bens materiais desejados, uma vez que, como as crianças referiam "as crianças não podem ter dinheiro" (António, 6 anos) e "os filhos portam bem para os pais comprarem coisas" (Edison, 6 anos). Porém, nem sempre o trabalho e a materialidade associada à instrumentalidade conferida ao papel do pai e da mãe na família sobressaiam enquanto aspetos positivos. A intensa vida profissional dos/as adultos/as leva, na atualidade, a que o tempo para brincar seja cada vez mais reduzido (T. Sarmento \& Freire, 2011). Sobressaia, desse modo, uma aparente falta de tempo sobre a qual se desconheciam todos os motivos, destacando-se, porém, a conceção atribuída ao brincar como uma atividade quase exclusiva da infância:
"António: eu no outro dia queria brincar com a minha mãe, mas só que ela estava cansada" (9 jan, 2017).

Os discursos das crianças mostravam também que, para além do fator económico ou material, a função do pai e da mãe surgia igualmente relacionada com a companhia e o auxílio à criança, sendo o/a adulto/a a sua figura de referência. Como referia a Alina (5 anos): "a melhor parte de ser mãe é ajudar" ou o Edison (6 anos) que afirmava que "[os pais] ajudam os seus filhos", o que remete para a importância da componente afetiva na relação pais/mães-filhos/as (Amaro, 2014; Aboim \& Wall, 2002). Tornou-se evidente, em certos casos, a diferenciação das funções assumidas em função do género, como veremos em maior profundidade no ponto seguinte.

\section{Dimensão dos papéis sociais assumidos}

Como Amaro (2014) refere, "para além dos papéis familiares, os indivíduos têm também papéis sociais (...), que geralmente se harmonizam entre si” (p. 104). Contudo, a dimensão que se mostrou profundamente marcada nos discursos das crianças foi, efetivamente, a dimensão da genderização dos papéis sociais assumidos pelo pai e pela mãe. Para a maioria das crianças, salvo alguns casos específicos, existiam funções de mãe e funções de pai, de que o discurso do Alexandre (6 anos) é exemplificativo: "ser pai é muito importante, por causa que ele é que compra a casa, compra o carro (...) [é mais cansativo ser pai] Porque o pai tem de trabalhar e as mães não tanto" (10 jan, 2017). Tornou-se percetível que as conceções das crianças se mostravam intrinsecamente interligadas ao seu contexto familiar e às suas experiências. Contudo, foi notória uma certa generalização relativamente à diferenciação de género nos discursos daquelas crianças. Talvez o facto de existir uma grande percentagem de mães desempregadas, permanecendo em casa grande parte do dia ou trabalhavam como empregadas domésticas, possa explicar (também) aqueles discursos: "Angelica (6 anos): o papel da mãe é elas terem de limpar a casa dos outros... a minha mãe faz isso! Afonso: a minha mãe também!"' (11 jan, 2017).

\section{"O que é ser filho/a e criança?". Análise dos discursos das crianças da sala 1}

De acordo com Graça (2015) refere, "o lugar da criança na família contemporânea encontra-se tão padronizado quanto as relações entre crianças e adultos" (p. 53), devendo, por isso, ser tomado em consideração "a condição social da infância enquanto expressão da realidade social" (p. 52), realidade esta definida pelas vivências e experiências de cada criança, marcado por perspetivas e conceções maioritariamente adultocêntricas. Apesar disso, surgiam, ainda que por vezes disfarçadas, convicções assertivas e determinadas acerca do que implica ser-se filho/a e criança.

\section{Ser filho/a}

A conceção de filho/a, para as crianças, surgiu, neste estudo, intimamente relacionada às funções que este/a exerce na família, às suas necessidades/afetividade, ao carinho/dádivas associadas e, por fim, ao respeito pela 
ordem adulta. Como necessidades associadas ao seu estatuto enquanto filhos/as, as crianças referiam as necessidades básicas, como uma "ter uma casa para viver (...) e comida" (Mariana, 6 anos). Algumas crianças identificavam "ser filho/a" como fácil, na medida em que eram os/as adultos/as que asseguravam as suas necessidades, reservando aos/às filhos/as o direito a brincar - "Ser filho é muito fixe! (Angelica, 6 anos) Sim! É só brincar, brincar! (Afonso, 6 anos) para outros, contrariamente, como difícil, devido à sua condição de dependência e obediência relativamente aos adultos. À condição de filho/a, dentro de uma família, as crianças pareciam associar sentimentos como a felicidade, remetendo-os, por exemplo, para presença e companhia dos pais/mães ou até a simples gestos dos mesmos em situações do dia-a-dia. Desse modo, tornava-se notório o impacto que a família efetivamente tem no enquadramento e regulação da vida de uma criança (Ferreira, 2006) que passa, na sua ótica, não só pela satisfação das necessidades mais básicas, como também pela dimensão afetiva, interligada ao próprio relacionamento da criança com o outro, na sua dimensão social e relacional. Já no que respeita às suas funções, a maioria das crianças identificava o brincar como a sua principal função. Ainda que sozinhas ou com outras crianças, as crianças encaravam a brincadeira como uma função da infância: "Rodrigo X. (6 anos): "ser filho é só brincar e também ver televisão e jogar no telemóvel dos pais" (11 jan, 2017). Contudo, enquanto algumas crianças identificavam funções da condição de filho/a associadas à infância, outras reportavam as suas funções às dificuldades associadas ao mundo adulto, privilegiando a sua função de ajudar, na condição de facilitar a vida dos pais que, na ótica de muitos, era tida como muito complicada: "Filipe (6 anos): (...) ser filho é ajudar os pais, porque ser pai e mãe é mesmo complicado" (13 jan, 2017). No limiar das suas funções, as crianças referiam-se ao respeito pela ordem adulta como o limite da sua agência enquanto filhos/as. $O$ respeito, a obediência, o cumprimento de regras ou tarefas, eram exemplos referidos pelas mesmas. Não podendo fazer/ter sempre tudo aquilo que desejam, as crianças evidenciavam um discurso marcado pela autoridade parental, vincada pela dimensão comportamental sujeita a regras, onde "[os filhos] não podem fazer asneiras" (Afonso, 5 anos).

\section{Ser criança}

Para além das funções/papéis atribuídos à condição de filho/a, evidenciou-se ainda, na análise dos discursos, a presença da caracterização da condição de criança, fortemente associada à irresponsabilidade, riscos e perigos, como afirmou o Miguel: "Crianças sozinhas é muito perigoso!" (6 anos).

Como aponta o estudo Duracell Toy Survey (2005), as crianças portuguesas são das que menos liberdade têm para brincar ao ar livre. Para Neto (2001), essa ausência de tempo espontâneo, imprevisível, de aventura e risco, proporcionado pelo contacto com o meio físico e natural, em função do tempo estruturado, organizado, planeado e uniformizado, torna-se um sério problema na sociedade atual (p. 31). Segundo este autor, "do estímulo ocasional passou-se a uma hegemonia do estímulo organizado, tendo como consequência a diminuição do nível de autonomia das crianças, com implicações graves na esfera do desenvolvimento motor, emocional e social [das mesmas]" (p. 31). De acordo com os discursos das crianças, pode concluir-se que "parece clara a consciência coletiva, expressa na voz de algumas crianças, acerca da condição desfavorável que [estas] detêm perante o perigo (...) sobretudo se estiverem sem a proteção dos pais ou adultos mais chegados" (Graça, 2015, p. 59). Apesar de não poderem deixar de ser considerados os perigos e respetivas preocupações dos pais e mães face aos mesmos, existe efetivamente, em Portugal, uma sobre proteção das crianças (pelo menos de uma grande parte) relacionada com medos e anseios por parte das famílias, influenciadoras até da inibição de um maior contacto com o exterior e brincadeiras ao ar livre, cruciais para o desenvolvimento integral. Contudo, considerando a infância enquanto categoria sociais de tipo geracional e as crianças como sujeitos competentes, com ação, vez e voz (Tomás, 2011), é necessário ouvir mais o que as crianças penas sobre os seus mundos de vida, "com competências para produzir activamente o quotidiano" (Almeida, 2009, p. 42), o que inclui o jardim de infância e a ação dos/as educadores/as. Estas competências, longe de homogéneas e consensuais, revelam conflitos, ideias pré-concebidas e pensamentos dicotómicos. Efetivamente ser criança é diferente de ser adulto para aquele grupo de crianças. Este discurso dominante encontra-se bastante enraizado nos discursos e nas práticas familiares e educativas, legitimado muitas vezes pelas próprias crianças, como vimos.

\section{Conclusão}

Da análise dos discursos das crianças, da observação e registo das brincadeiras, improvisações e jogos dramáticos realizados, tornou-se possível identificar discursos e lógicas de classificação social, em função do género e da idade. As crianças assumiram e naturalizam a ordem adulta a partir de uma lógica de superioridade, dependência e conformismo dos/as adultos/as em relação às crianças. $\mathrm{O}$ discurso dominante das crianças da sala 1 remete a condição da infância para uma pretensa irresponsabilidade que só os/as adultos/as conseguem regular. Outro dado importante refere-se ao brincar como atividade exclusiva das crianças. De acordo com as mesmas, a responsabilidade dos/as adultos/as, bem como a sua falta de tempo impossibilita (também) espaços e tempos de brincadeira nos quotidianos familiares. É, assim, revelada uma realidade social, captada através do olhar e das vozes da infância, que deve impelir os/as profissionais da educação a refletir e a intervir.

\section{Referências}

Aboim, S. \& Wall, K. (2002). Tipos de família em Portugal: interacções, valores, contextos. Análise Social, XXVII (163), 475-506 http://analisesocial.ics.ul.pt/documentos/1218732849 L9wOF3hb9Nc24JA5.pdf 
Almeida, A. N. (2009). Para uma Sociologia da Infância - Jogos de olhares, pistas para a investigação. Lisboa: ICSs.

Amaro, F. (2014). Sociologia da Família. Lisboa: Pactor.

Bardin, L. (1979). Análise de Conteúdo. Lisboa: Edições 70.

Christensen, P. \& James, A. (2005). Investigação com Crianças - Perspectivas e Práticas. Porto: Escola Superior de Educação Paula Frassinetti.

Cunha, V. (2007). Lugar dos Filhos - Ideais, Práticas e Significados. Lisboa: ICS.

Duracell (2015). European Duracell Toy Survey. em https://tinyurl.com/jew8wth

Ferreira, M. (2006). "Tá na hora d'ir pr'à escola!”; “Eu não sei fazer esta, senhor professor!" ou... Brincar às escolas (JI) como um modo das criança darem sentido e negociarem as relações entre a família e a escola. Interacções, 2 (2), 27-58 http://revistas.rcaap.pt/interaccoes/article/view/290

Graça, M. (2015). "Professora, tu agora já sabes mais um bocado do que é ser filhos e essas coisas da família?": Um trabalho de dupla reflexão e coprodução de dados com crianças em idade pré-escolar. Da Investigação às Práticas. 6(1), 50-68 http://www.scielo.mec.pt/pdf/inp/v6n1/v6n1a04.pdf

Neto, C. (2001). A criança e o jogo: perspectivas de investigação. In B. Pereira, A. Pinto (Coord.). A Escola e a Criança em Risco - Intervir para Prevenir (pp. 31-51). Porto : Edições ASA.

Nörnberg, M. (2007). O lugar do cuidado na formação de professores. Diálogo, 11, 211-234 https://biblioteca.unilasalle.edu.br/docs_online/artigos /dialogo/2007_n11/mnornberg.pdf

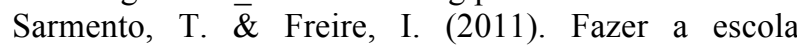 acontecer: A colaboração crianças-professores-pais como prática de cidadania. Revista ELO, 18, 37-48

Tomás, C. (2011). "Há muitos mundos no mundo". Cosmopolitismo, participação e direitos da criança. Porto: Afrontamento. 